\title{
Minireview
}

nephron

Clinical

Practice

\section{Novel Hypoglycaemic Agents: Considerations in Patients with Chronic Kidney Disease}

\section{Fran Game}

Department of Diabetes and Endocrinology, Derby Hospitals NHS FT, Derby, UK

\section{Key Words}

Type 2 diabetes · Renal impairment · Drug treatment

\begin{abstract}
One of the commonest complications of type 2 diabetes is renal disease. Treatment guidelines emphasise the need for tight glycaemic control to reduce the development of future complications; however, with the development of renal impairment, the benefit of tight glycaemic control must be weighed against the potential for adverse effects from drugs or their metabolites which may accumulate. In this article, the glucose-lowering drugs used in the management of type 2 diabetes are reviewed, with particular emphasis on newer guidelines and agents.

(C) 2014 S. Karger AG, Basel
\end{abstract}

\section{Introduction}

It is known that there were 2.9 million people in the UK registered with diabetes mellitus in 2011, with a further million people estimated to have the disease but either unregistered or undiagnosed [1]. The majority of these patients will have type 2 diabetes, due in part to an aging and more sedentary population. The cost of this disease to the NHS is extremely high, estimated at GBP 10 billion in 2010/2011, the majority of which is related to treatment of complications [1].

Of these complications, renal disease is one of the most common. Estimates of the prevalence vary depending on the population studied, but range from $18 \%$ to over $30 \%$ of all people with diabetes [2]. Treatment algorithms designed to reduce the development or progression of the complications of diabetes emphasise the need for good glycaemic control; however, with the development of renal impairment the benefit of tight glycaemic control must be weighed against the potential for adverse effects from drugs or their metabolites which may accumulate.

This article reviews the treatments available for patients with type 2 diabetes and the impact of renal impairment on their metabolism, with an emphasis on agents introduced within the last decade.

\section{Traditional Glucose-Lowering Treatments}

\section{Metformin}

Metformin, currently considered the drug of first choice for most patients with type 2 diabetes, has been

\section{KARGER}

E-Mail karger@karger.com

www.karger.com/nec
(C) 2014 S. Karger AG, Basel

$1660-2110 / 14 / 1261-0014 \$ 39.50 / 0$
Dr. Fran Game

Department of Diabetes and Endocrinology, Derby Hospitals NHS FT Uttoxeter Road

Derby DE22 3NE (UK)

E-Mail frances.game@nhs.net 
used for over 50 years in Europe. Its place in the treatment algorithm is probably due to the fact that it is weight neutral and reduces the risk of development of cardiovascular disease and mortality [3]. Although its exact mechanism of action is not completely understood, it probably has an action on hepatic glucose output as well as facilitating insulin-mediated peripheral glucose uptake. Metformin, however, is eliminated unchanged via the kidneys by glomerular filtration and tubular secretion, and therefore may accumulate if the patient has renal dysfunction.

The most serious adverse effect of metformin is the development of lactic acidosis, but in reality this is very rare at about 5/100,000 patient-years [4]. Although mortality has been estimated to be up to $40 \%$, lactic acidosis is often accompanied by other predisposing conditions such as severe heart failure, hepatic dysfunction, acute kidney injury, hypoxia and shock. In many cases, it may be that metformin is not the causal agent, and that the severe lactic acidosis is due to the underlying condition. Given such high mortality, however, it is important to ensure that patients understand the need to discontinue metformin in case of dehydration. It used to be standard in the UK to discontinue metformin in all patients for $48 \mathrm{~h}$ after the administration of intravenous contrast material. However, current guidelines [5], which recognise the risk of lactic acidosis is extremely low and that stopping the drug causes considerable problem to patients and clinicians alike, recommend that there is no need to stop metformin if the estimated glomerular filtration rate (eGFR) is greater than $60 \mathrm{ml} / \mathrm{min}$ and that discontinuation in other patients should be in consultation with the referring clinician. The current NICE guidance on the use of metformin in patients with renal impairment also reflects the recognition that lactic acidosis is rare. The advice is to review the dose of metformin if serum creatinine exceeds 130 $\mu \mathrm{mol} / \mathrm{l}$ or if the eGFR is below $45 \mathrm{ml} / \mathrm{min}$, and it should be stopped if serum creatinine exceeds $150 \mu \mathrm{mol} / \mathrm{l}$ or the eGFR is less than $30 \mathrm{ml} / \mathrm{min}$ [6].

\section{Insulin Secretagogues}

\section{Sulphonylureas}

Like metformin, sulphonylureas have been in use in patients with diabetes for many years. The first-generation sulphonylureas (e.g. chlorpropamide) are no longer used because of the risk of prolonged hypoglycaemia. However, even though the second-generation sulphonyl- ureas (e.g. glibenclamide, glyburide, glimepiride, gliclazide) have shorter half-lives, they are not without significant risk of hypoglycaemia, particularly in those with renal impairment due to the accumulation of active metabolites. If necessary, the shorter-acting drug gliclazide, which is mainly metabolised in the liver, can be used, but patients must be able to monitor blood-glucose concentration and be aware of the risk of, and the management of, hypoglycaemia.

\section{Meglitinides}

Two meglitinides are available: repaglinide and nateglinide. Characterised by a rapid onset and a short duration of action, they are less potent than sulphonylureas and are taken pre-prandially. As a result, the risk of hypoglycaemia is lower than with sulphonylureas. Repaglinide is mostly metabolised by the liver and could therefore be used in patients with low renal function, although some dose adjustment is required [7]. Nateglinide is rapidly degraded by the liver to mostly inactive or weakly active metabolites which are eliminated in the urine [8], and so can be considered patients with poor renal function, again with dose reduction. Unlike repaglinide, however, it does not have a license for monotherapy in the UK - its use being restricted to dual therapy with metformin [8].

\section{Thiazolidinediones}

Pioglitazone is now the only thiazolidinedione available in Europe. It is mainly metabolised in the liver and although a significant amount of active metabolites are eliminated in the urine, there is no need for dose reduction in those with renal impairment [9]. However, the drug is well known to cause fluid retention and can precipitate heart failure. For this reason most clinicians would avoid it in patients with renal disease.

\section{Newer Agents}

\section{Agents Affecting the Incretin Pathway}

It is well recognised that insulin secretion from pancreatic beta-cells is much higher after an oral glucose load than after an intravenous load given the same rise in blood glucose. This is the 'incretin effect' and is caused by gut hormones released in response to food arriving in the upper gastrointestinal tract. Glucagon-like peptide-1 (GLP-1), an incretin hormone, stimulates the release of insulin from pancreatic beta-cells, reduces glucagon release from alpha-cells, and causes a decrease in gastric 
emptying and an increase in the feeling of satiety [10]. GLP-1 is cleared form the circulation within a few minutes, being rapidly broken down by the enzyme dipeptidyl peptidase-4 (DPP-4). This has allowed the development of agents that block this enzyme and hence augment the effect of GLP-1 on blood glucose.

\section{DPP-4 Inhibitors}

Taken orally, these agents block DPP-4 as above, reducing glucose (HbAlc reduction on average $0.5-1.1 \%$ ) but with a low risk of hypoglycaemia, and are weight neutral. Side effects include nasopharyngeal symptoms, headaches and rarely angio-oedema [10]. Pancreatitis has also been rarely reported and patients must be counselled to stop the drug and seek medical advice should they develop severe abdominal pain [11]. There are no long-term outcome data from randomised controlled trials, although post hoc analysis of a number of small trials suggests that the risk of cardiovascular disease may be reduced [12].

Four agents are currently available in the UK and have been included in the most recent NICE clinical guideline [6] for the management of type 2 diabetes. They are considered second-line treatment (after metformin) in place of a sulphonylurea only if there is a significant risk of hypoglycaemia or if sulphonylureas are not tolerated, or in addition to a sulphonylurea if metformin is not tolerated. Third-line treatment in addition to metformin and a sulphonylurea may be considered if insulin is not appropriate, or when a thiazolidinedione is contraindicated or not tolerated. The agent should be discontinued after 6 months if there has not been a reduction in $\mathrm{HbAlc}$ of $0.5 \%$.

Sitagliptin, vildagliptin, saxagliptin and linagliptin differ in their renal excretion and therefore should be handled differently in patients with impairment of renal function.

\section{Sitagliptin}

Sitagliptin is largely excreted unchanged in the urine, but can be used with dose reduction in patients with renal impairment [13]. The normal dose [100 mg once a day (o.d.)] should be halved (50 mg o.d.) for patients with moderate renal impairment (creatinine clearance $\geq 30$ to $<50 \mathrm{ml} / \mathrm{min}$ ), and halved again ( $25 \mathrm{mg}$ o.d.) for those with severe impairment $(<30 \mathrm{ml} / \mathrm{min})$ or end-stage renal disease requiring renal replacement therapy.

\section{Vildagliptin}

Vildagliptin is metabolised mostly in the kidneys to inactive metabolites which are then renally excreted [14]. Usually given at a dose of $50 \mathrm{mg}$ twice daily, this should be halved to $50 \mathrm{mg}$ o.d. in patients with moderate or severe renal impairment and it can be used with caution in those with end-stage renal disease.

\section{Saxagliptin}

Saxagliptin is metabolised mainly in the liver to an active metabolite that is renally excreted [15]. The usual dose (5 mg o.d.) should be reduced to $2.5 \mathrm{mg}$ o.d. in patients with moderate or severe renal impairment. It is not recommended for use in those on renal replacement therapy.

\section{Linagliptin}

Linagliptin is excreted almost entirely unchanged in bile, making it a useful drug for patients with any degree of renal impairment without dose adjustment [16], including (with caution) those requiring renal replacement therapy.

\section{GLP-1 Receptor Agonists}

GLP-1 receptor agonists (exenatide, liraglutide, lixisenatide) are given by subcutaneous (s.c.) injection and have the useful advantage of promoting weight loss as well as controlling blood glucose (average $\mathrm{HbAlc}$ reductions of $0.7-1.5 \%)$. They are not cheap agents, however, and in England and Wales their use is restricted to those patients who have a BMI $\geq 35.0$ and who fail to achieve adequate blood glucose control despite taking two oral hypoglycaemics [7]. Treatment should be discontinued if there is not a reduction in $\mathrm{HbAlc}$ of at least $1.0 \%$ and weight loss of at least 3\% of initial body weight at 6 months. Due to the effect of these agents on gastric emptying, side effects are mainly gastro-intestinal: nausea, vomiting and diarrhoea. It may be these that are behind the documented, but rare, reports of acute renal failure in patients on GLP-1 agonists [17]. As with DPP-4 inhibitors, acute pancreatitis has been reported and, as above, patients need to be told to seek help if they develop severe abdominal pain [17].

\section{Exenatide}

Exenatide (starting dose $5 \mu \mathrm{g}$ s.c. twice daily, increasing to $10 \mu \mathrm{g}$ twice daily after 14 days) is mainly eliminated by glomerular filtration, followed by proteolytic break- 
down. In patients with mild-to-moderate renal impairment $(30-50 \mathrm{ml} / \mathrm{min})$, exenatide clearance is slightly reduced compared to subjects with no renal impairment, and the dose escalation from 5-10 $\mu \mathrm{g}$ should thus proceed with caution. In patients with severe renal impairment or dialysis patients, clearance is reduced by about $80 \%$ and is therefore not recommended if creatinine clearance is $<30 \mathrm{ml} / \mathrm{min}$ [18].

\section{Liraglutide}

Liraglutide is given once daily by s.c. injections (0.6$1.8 \mathrm{mg}$ ). Its efficacy with regard to HbAlc lowering may be slightly better than exenatide due to the lowering of fasting glucose [19]. Its effect on weight though is about the same [20]. Liraglutide is metabolised in a similar manner to large proteins, no specific organ is responsible for its elimination and it shows no reduced clearance in patients with renal impairment. Patients with mild renal impairment therefore require no dose adjustment. Currently, however, there is very limited experience with liraglutide in patients with moderate renal impairment and no experience in those with severe renal impairment. It is therefore currently contraindicated in these settings [19].

\section{Lixisenatide}

Lixisenatide is administered once daily by s.c. injection (staring dose $10 \mu \mathrm{g} /$ day increasing to $20 \mu \mathrm{g}$ after 14 days). One study [21] has shown clinical non-inferiority to exenatide, although the validity of that conclusion has been questioned. However, HbAlc reductions of $0.6-$
$0.9 \%$ on average have been achieved in clinical trials. As a peptide, lixisenatide is eliminated through glomerular filtration, followed by tubular reabsorption and subsequent metabolic degradation. In subjects with moderate and severe renal impairment, accumulation of lixisenatide in the circulation has been noted [22]. No dose adjustment is recommended for patients with mild renal impairment (creatinine clearance: $50-80 \mathrm{ml} / \mathrm{min}$ ), but as there is limited therapeutic experience in patients with moderate renal impairment (creatinine clearance: $30-50 \mathrm{ml} / \mathrm{min}$ ), lixisenatide should be used with caution and is contraindicated in those with severe renal impairment.

\section{Sodium-Glucose Cotransporter-2 Inhibitors}

One of a new class of agents, dapagliflozin is currently the only one marketed in the UK. It is an inhibitor of the sodium-glucose cotransporter-2 that blocks the reabsorption of glucose in the kidneys and promotes excretion of excess glucose in the urine. It is an appealing class of agents because of the low risk of hypoglycaemia and lack of weight gain. Adverse reactions include urinary tract and genital infection, back pain, dysuria, polyuria, dyslipidaemia, and elevated haematocrit [23]. However, due to its mode of action, dapagliflozin, or indeed any of this class of agents not yet marketed in the UK, is not recommended for use in people with any degree of renal impairment (eGFR $<60 \mathrm{ml} / \mathrm{min}$ ) because its efficacy is dependent on renal function.

\section{References}

1 Diabetes in the UK 2012. Key statistics on diabetes. Diabetes UK. http://www.diabetes. org.uk/Documents/Reports/Diabetes-in-theUK-2012.pdf (accessed September 15, 2013).

2 SIGN. Management of Diabetes. Edinburgh, SIGN, 2010. http://www.sign.ac.uk/guidelines/fulltext/116/index.html (accessed September 15, 2013).

- 3 Effect of intensive blood-glucose control with metformin on complications in overweight patients with type 2 diabetes (UKPDS 34). Lancet 1998;352:854-865.

-4 Nye HJ, Herrington W: Metformin: The safest hypoglycaemic agent in chronic kidney disease? Nephron Clin Pract 2011;118:380383.
5 The Royal College of Radiologists. Standards for intravenous contrast agent administration to adult patients, ed 2. 2010. http://www.rcr. ac.uk/docs/radiology/pdf/BFCR(10) 4 Stand_contrast.pdf (accessed September 20, 2013).

6 National Institute for Health and Care Excellence. The management of type 2 diabetes (CG87). 2009. http://guidance.nice.org.uk/ cg87 (accessed October 10, 2013).

7 Repaglinide. Summary of product characteristics. www.medicines.org.uk/EMC/medicine/ 18980/SPC/ (accessed September 15, 2013).

8 Nateglinide. Summary of product characteristics. www.medicines.org.uk/emc/medicine/ 4622/SPC/ (accessed September 15, 2013).

9 Pioglitazone. Summary of product characteristics. http://www.medicines.org.uk/emc/ medicine/4236/SPC/ (accessed September 15, 2013).
10 Burgmaier M, Heinrich C, Marx N: Cardiovascular effects of GLP-1 and GLP-1 based therapies: implications for the cardiovascular continuum in diabetes? Diabetic Med 2013; 30:289-299.

11 Dipeptidylpeptidase-4 inhibitors ('gliptins'): risk of acute pancreatitis. MRHA drug safety update. http://www.mhra.gov.uk/Safetyinformation/DrugSafetyUpdate/CON185628 (accessed September 15, 2013).

12 Jose T, Inzucchi SE: Cardiovascular effects of the DPP-4 inhibitors. Diab Vasc Dis Res 2012; 9:109-116.

13 Sitagliptin. Summary of product characteristics. www.medicines.org.uk/emc/medicine/ 19609 (accessed September 16, 2013).

14 Vildagliptin. Summary of product characteristics. www.medicines.org.uk/emc/medicine/ 20734 (accessed September 16, 2013). 
15 Saxagliptin. Summary of product characteristics. www.medicines.org.uk/emc/medicine/ 22315 (accessed September 16, 2013).

16 Linagliptin. Summary of product characteristics. www.medicines.org.uk/EMC/medicine/ 25000 (accessed September 16, 2013).

17 Exenatide (Byetta): risk of severe pancreatitis and renal failure. http://www.mhra.gov.uk/ Safetyinformation/DrugSafetyUpdate/ CON088117 (accessed September 15, 2013).

18 Exenatide: Summary of product characteristics. http://www.medicines.org.uk/emc/medicine/19257/SPC/ (accessed September 15, 2013).
19 Liraglutide: Summary of product characteristics. http://www.medicines.org.uk/emc/medicine/21986/SPC (accessed September 15, 2013).

20 Pratley RE, Nauck M, Bailey T, Montanya E, Cuddihy R, Filetti S, et al: Liraglutide versus sitagliptin for patients with type 2 diabetes who did not have adequate glycaemic control with metformin: a 26-week, randomised, parallel-group, open-label trial. Lancet 2010;375: 1447-1456.
21 Rosenstock J, Raccah D, Korányi L, Maffei L, Boka G, Miossec P, Gerich JE: Efficacy and safety of lixisenatide once daily versus exenatide twice daily in type 2 diabetes inadequately controlled on metformin: a 24-week, randomized, open-label, active-controlled study (GetGoal-X). Diabetes Care 2013;36:29452951.

22 Lixisenatide: Summary of product characteristics. http://www.medicines.org.uk/emc/ medicine/27405/SPC/ (accessed September 15, 2013).

23 Dapagliflozin: Summary of product characteristics. http://www.medicines.org.uk/emc/ medicine/27188/SPC/ (accessed September $15,2013)$. 